\title{
Community and hospital pharmacists in Europe: encroaching on medicine?
}

\author{
Livio Garattini ${ }^{1} \cdot$ Anna Padula $^{1} \cdot$ Pier Mannuccio Mannucci $^{2}$
}

Received: 4 August 2020 / Accepted: 4 September 2020 / Published online: 13 September 2020

(c) Società Italiana di Medicina Interna (SIMI) 2020

\begin{abstract}
Pharmacy has been historically regarded as a discipline between health and chemistry devoted to drug development, production, and compounding. These tasks have been almost lost with the industrial manufacturing, and dispensing remains the main activity of pharmacists. Hospital pharmacists are usually employees in their workplace, while the professional framework of community pharmacists is very different, being pharmacies predominantly private shops in almost all European countries. In the last years pharmacists have strongly advocated that the focus of their services should switch from 'product' to 'patient'. Clinical pharmacy and pharmaceutical care are the two most cited concepts to support this shift. Clinical pharmacy was originally defined as the area of pharmacy concerned with the science and practice of rational medication use, pharmaceutical care as the responsible provision of drug therapies to achieve definite outcomes. The practice of clinical pharmacy should embrace the philosophy of pharmaceutical care. The new wave of pharmacists' patient-centered care in Europe still seems to be a reaction against the loss of their traditional professional role after the drug manufacturing revolution. To depict a realistic scenario for progress, it is worth differentiating between hospital and community. Hospital pharmacists should strengthen their pivotal role of medication gatekeepers to improve among clinicians the appropriateness of drug prescriptions and generate savings in expenditures. Any proposal for clinical services provided by community pharmacists is inevitably affected by the issue of their potential remuneration, especially in countries where the remuneration for reimbursable drugs is still a proportion of the retail price.
\end{abstract}

Keywords Pharmacy $\cdot$ Hospital $\cdot$ Community

\section{Historical background}

Pharmacy has been historically regarded as a discipline between health and chemistry devoted to drug development, production, and compounding [1]. Until relatively late in the last millennium the vast majority of pharmacists used to make drugs, regardless of whether they worked in hospital or in community. These early tasks have been substantially lost with the large-scale industrial manufacturing of drugs, so that their dispensing remains the main activity of pharmacists. In the long run these changes have weakened the original value of the combination of pharmacist's profession

Livio Garattini

livio.garattini@marionegri.it

1 Institute for Pharmacological Research Mario Negri IRCCS, Ranica, BG, Italy

2 IRCCS “Ca' Granda Maggiore Policlinico” Hospital Foundation, Milan, Italy and education [2]. Although still focused on scientific topics (e.g., physics and biology), the university education of pharmacists has been inevitably influenced by the different national regulations for the profession, especially in the community working domain, which remains by far the most important labor market for pharmacy graduates. At present, pharmacists' education shows a wide range of different arrangements in European countries, starting from the shortest duration of graduation, which ranges from 3 (in the Scandinavian countries), 5 (in Italy), up to 6 years (in France and the Netherlands) [2].

In the last years pharmacists have strongly advocated that the focus of their services as drug therapy has increasingly switched from the 'product' to the 'patient' regardless of where they work [3]. Shifting the slogan from 'getting the right drug to each patient' to 'getting the drug therapy right for each patient' [4], both hospital and community pharmacists are expected to increasingly contribute to reduce clinical errors and eventually improve the efficient use of health 
care resources [5]. Clinical pharmacy and pharmaceutical care [6] are the two most cited concepts meant to support this trend (see third section).

Here, first we analyze the present role of pharmacists in hospital and community pharmacies. Then we look at the clinical pharmacy and pharmaceutical care narratives backing the pharmacists' claim to patient-centered care. Finally, we depict a possible future strategy for a common European policy in the two settings.

\section{Two clear-cut settings}

Patient drug therapy can be divided into three steps: prescription, distribution and administration. Traditionally, each step can be easily delegated to a specific health professional in hospital - respectively the physician, the pharmacist and the nurse [7]. Fostering the hospital pharmacist's role from simply moving boxes and handling supplies to providing clinical services to patients would imply that seven 'rights' are always fulfilled for all pharmaceutical therapies [8]: right patient, dose, route, time, drug, information and documentation. The most recent cogent argument is why hospital pharmacists are not allowed to prescribe drugs in Europe, like in other continents [7]. Although opposed by the medical profession from the outset, this already happens in England and Ireland, a move possibly favored by the shortage of physicians in these countries. Besides requiring adequate clinical knowledge (diagnostic skills included), the request to extend prescribing rights is likely to bring hospital pharmacists, who are usually employees in their workplace, into conflict with their medical colleagues. It might also involve legal litigations with patients and their relatives in case of negative outcomes, a costly risk that many European hospital pharmacists may not necessarily be prepared to share with clinicians.

The professional framework of European pharmacists in the community is very different from those acting in hospitals. Community pharmacies are predominantly private shops in almost all European countries [9], mainly owned by single pharmacists (like in France, Italy and Spain) or chains (like in the NL and the UK). Therefore, management strategies are crucially directed towards profitability. Community pharmacists have always had a potential 'conflict of interest' when employed in a private pharmacy, owing to their dual role of health professionals and commercial agents. Clear evidence of the importance of commercial reasoning is the wide range of products other than drugs sold in private pharmacies, including some that are in conflict with pharmacist's education (e.g., homeopathic products). The vast majority of European community pharmacists are still professionally responsible only for checking prescriptions and then for delivering the requested medications. To our knowledge, the only (partial) exception is represented by Dutch community pharmacists, who can intervene on prescriptions if these fail to respect national guidelines or do not seem appropriate for that individual patient [10]. Conversely, Italian community pharmacists employed in para-pharmacies and health corners of large retail outlets (which are obliged to employ them) are forbidden to dispense ethical medicines despite their university degree, being only allowed to provide overthe-counter drugs [11]. The only realistic justification for this odd limit is likely to be the defense of financial privileges matured by community pharmacies hereditarily owned by single pharmacists, reimbursed drugs being still around $60 \%$ of the total turnover.

\section{Two overlapping concepts}

Clinical pharmacy was originally defined as the area of pharmacy concerned with the science and practice of rational medication use [12]. Thanks to this discipline, pharmacists are expected to provide patient care meant to optimize drug therapies. Pharmaceutical care was originally defined as the responsible provision of drug therapies in order to achieve definite outcomes and the ultimate goal to improve patients' quality of life [13]. The underlying recommendation was to move toward a patient-centered philosophy of clinical practice aimed at improving therapeutic outcomes. Although a recent survey found evidence that pharmaceutical care is mainly associated with community pharmacies in Europe [14], the two concepts are widely used and mixed in both primary and secondary care despite various attempts to further define and differentiate them [6]. Trying to put it briefly, the practice of clinical pharmacy should embrace the philosophy of pharmaceutical care [12], the patient being the primary target for both.

From theory to practice, patient-centered care should make use of pharmacists to advise patients directly for medication therapies and collaborate with other health professionals (especially physicians and nurses) in the frame of multidisciplinary teams [12]. Consistently with pharmaceutical care, the former activity should involve a narrative approach meant to develop communication and empathy skills with patients, while the latter would imply providing additional patient-related services of clinical pharmacy [6]. Owing to the continuously increasing numbers of elderly people, multimorbidities have become prevalent in Europe and polypharmacy is an obvious consequence [3], with many patients taking five or more medicines daily. So, medication review-a structured evaluation of a patient's medicine regimens with the aim of optimizing them and improving health outcomes [15] - has become a frequently cited concept in the literature, being a sort of 'umbrella term' covering drug 
therapy adherence and reconciliation between medicines too [16].

In general, although it seems obvious to expect positive results from clinical pharmacy services and pharmaceutical care philosophy of practice, they are hard to prove on the basis of clinical evidence. Many interventions are of difficult standardization, and this is also true for their related outcomes in trials [7, 9]. Yet most studies have been conducted on small samples in single facilities, probably prompted by pharmacists to demonstrate the usefulness of their services, so that results cannot be generalized. On account of the scant clinical evidence, cost-effectiveness analyses focused on trade-offs between the additional costs of clinical pharmacy services and potential savings on other healthcare services at a local level may only add further confusion. However, needless to say, each pharmacist is able to provide a good clinical service regardless of the healthcare setting, just like any other health professional who offers her/his job in the interests of patients.

\section{Policy implications}

The new wave of pharmacists' patient-centered care in Europe still seems to be a reaction against the loss of their traditional professional role after the drug manufacturing revolution, somehow masking a perceived identity crisis by shifting towards clinical medicine [17]. To envisage a realistic scenario for a rational prospective evolution of the pharmacist's role in health care, one must obviously differentiate the hospital and community settings, very different in terms of healthcare provision.

\section{Hospital}

Rather than claiming prescription rights, hospital pharmacists should strengthen their pivotal role of medication 'gatekeepers' in the frame of a close collaboration with clinicians, so as to improve prescription appropriateness and eventually generate savings in drug expenditures [18]. Being in the right position as experts to advise clinicians on drug kinetics and dynamics, hospital pharmacists may be able to reinforce their role by specializing in specific therapeutic areas and affirming their independent opinions within multidisciplinary teams to enhance cost-effective prescriptions. After medical specialists make their diagnosis and prescribe a given therapy, hospital pharmacists might check that the most appropriate drugs have been selected, especially for patients in polypharmacy such as the elderly and those with chronic conditions, to minimize the risks of drug interactions and adverse reactions. Moreover, to help free up work time of their clinical colleagues, hospital pharmacists might discuss with problematic patients the preferred route of drug administration and/or form.

\section{Community}

Community pharmacists are among the most easily accessible and highly visible healthcare professionals in primary care, and are ideally in a very good position to advise patients directly on medication therapies. They can also encourage their adherence to prescriptions (especially for multi-morbid patients), possibly curtailing drug-related morbidity and mortality. However, the proposals for clinical services provided by community pharmacists, like that recently approved by the Italian Government on the detection of risk factors (e.g., glycaemia and cholesterolemia assays), are inevitably affected by the crucial issue of their potential remuneration. Many European community pharmacists still work in small to medium shops, which must ensure returns on their investments [19], as the sky-high prices of face masks during the very first wave of COVID-19 pandemic in Italy has recently shown. The major marketing advantage of pharmacies is attracting extra customers for other health products and services owing to their monopoly on reimbursable drugs. It would be useful to establish a systematic regulation for remuneration of both drug delivery and additional clinical services. Otherwise pharmaceutical care remains a disputable concept in practice, potentially driven by commercial incentives at the time of intervention on prescriptions. This is especially true in a country like Italy where the remuneration for reimbursable drugs is still a (high) proportion of the retail price, and not like in the UK a (low) flat fee for the dispensing service delivered [20]. Last but not least, a minimum of three years for graduation should probably be enough for pharmacists to start working in a community pharmacy and to avoid feeling too qualified for their daily activities of drug dispensing only. By the way, this is the duration in all European faculties but human and veterinary medicine.

In conclusion, despite the weakness of the European Union in this field (inherited from a piecemeal national framework) and its present lack of political strength, we are still firmly convinced that European solutions are potentially the best in the long run.

Acknowledgements LG would like to thank his friend Duvan Finazzebri for his useful comments on the first draft of the manuscript.

Funding No sources of funding were used to conduct this study or prepare this manuscript.

\section{Compliance with ethical standards}

Conflict of interest Livio Garattini, Anna Padula and Pier Mannuccio Mannucci have no conflicts of interest directly relevant to this article. 
Statements on human and animal rights This article does not contain any studies with human participants or animals performed by any of the authors.

Informed consent None.

\section{References}

1. Pearson GJ (2007) Evolution in the practice of pharmacy—not a revolution! CMAJ 176(9):1295-1296

2. Garattini L, Padula A (2018) From pharmacy faculty to pharmacy shop: still a logical pathway in Europe? Drugs Ther Perspect 34(2):85-88

3. Moltó-Puigmartí C, Vonk R, van Ommeren G, Hegger I (2018) A logic model for pharmaceutical care. J Health Serv Res Policy 23(3):148-157

4. Kehrer JP, Eberhart G, Wing M, Horon K (2013) Pharmacy's role in a modern health continuum. Can Pharm J 146(6):321-324

5. Atkinson J (2017) The Country profiles of the PHARMINE Survey of European higher educational institutions delivering pharmacy education and training. Pharmacy (Basel) 5(3):E34

6. Franklin BD, van Mil JW (2005) Defining clinical pharmacy and pharmaceutical care. Pharm World Sci 27(3):137

7. Garattini L, Padula A (2018) Hospital pharmacists in Europe: between warehouse and prescription pad? Pharmacoecon Open 2(3):221-224

8. Anonymous (2014) The European statements of hospital pharmacy. Eur J Hosp Pharm 21:256-258

9. Garattini L, Padula A (2018) Pharmaceutical care in Italy and other European countries: between care and commerce? Postgrad Med 130(1):52-54

10. Teichert M, Schoenmakers T, Kylstra N et al (2016) Quality indicators for pharmaceutical care: a comprehensive set with national scores for Dutch community pharmacies. Int J Clin Pharm 38(4):870-879
11. Garattini L, van de Vooren K, Curto A (2012) Will the reform of community pharmacies in Italy be of benefit to patients or the Italian National Health Service? Drugs Ther Perspect 28(11):23-26

12. Anonymous (2008) The definition of clinical pharmacy. American College of Clinical Pharmacy. Pharmacotherapy 28(6):816-817

13. Hepler CD, Strand LM (1990) Opportunities and responsibilities in pharmaceutical care. Am J Hosp Pharm 47(3):533-543

14. Dreischulte T, Fernandez-Llimos F (2016) Current perceptions of the term clinical pharmacy and its relationship to pharmaceutical care: a survey of members of the European Society of Clinical Pharmacy. Int J Clin Pharm 38(6):1445-1446

15. Griese-Mammen N, Hersberger KE, Messerli M, Leikola S, Horvat N, van Mil JWF, Kos M (2018) PCNE definition of medication review: reaching agreement. Int J Clin Pharm 40(5):1199-1208

16. Blenkinsopp A, Bond C, Raynor DK (2012) Medication reviews. Br J Clin Pharmacol 74(4):573-580

17. Garattini L, Padula A, Freemantle N (2020) Do European pharmacists really have to trespass on medicine? Eur J Health Econ. https ://doi.org/10.1007/s10198-020-01185-w(Epub ahead of print)

18. Garattini L, Padula A (2017) 'Appropriateness' in Italy: a 'magic word' in pharmaceuticals? Appl Health Econ Health Policy 15(1):1-3

19. Soares IB, Imfeld-Isenegger TL, Makovec UN, Horvat N, Kos M, Arnet I, Hersberger KE, Costa FA (2020) A survey to assess the availability, implementation rate and remuneration of pharmacistled cognitive services throughout Europe. Res Social Adm Pharm 16(1):41-47

20. Garattini L, Curto A, Padula A (2016) Reimbursable drug classes and ceilings in Italy: why not only one? Eur J Health Econ 17(8):923-926

Publisher's Note Springer Nature remains neutral with regard to jurisdictional claims in published maps and institutional affiliations. 